A Comparison of Sex Offenders and Other Types of Offenders Referred to Intellectual Disability Forensic Services

\author{
William R Lindsay ${ }^{1,2}$ \\ Derek Carson 2 \\ Antony $\mathrm{J}^{\text {Holland }}{ }^{5}$ \\ Amanda M Michie ${ }^{4}$ \\ John L Taylor ${ }^{3}$ \\ Marie Bambrick ${ }^{5}$ \\ Gregory O’Brien ${ }^{3}$ \\ Jessica Wheeler ${ }^{5}$ \\ Lesley Steptoe
}

1. Castlebeck, Darlington, UK

2. University of Abertay, Dundee, UK

3. University of Northumbria, Newcastle, UK

4. NHS Lothian, UK

5. University of Cambridge, UK

Correspondence: Prof Bill Lindsay, Monroe House, 119 Americanmuir Road, Dundee, DD3 9AG, Scotland, UK. Email: billindsay@castlebeck.com 
Summary

This study compared 131 sex offenders with ID and 346 other types of offenders with ID using case file records.. All the females in the study were non sexual offenders. Significantly more sexual offenders were referred from court and criminal justice services while significantly fewer were referred from secondary healthcare. A higher percentage of sex offenders had some form of legal status at time of referral. Greater proportions of non sexual offenders were referred for aggression, damage to property, substance abuse and fire setting while only the sex offenders had an index sex offence. For previous offending, the non sexual offenders had higher rates of aggression, cruelty and neglect of children, property damage and substance abuse while the sexual offenders had higher rates of previous sexual offending. For psychiatric disturbance and adversity in childhood, only ADHD showed a significant difference between groups with the non sexual offenders recording higher rates.

Keywords: intellectual disability; sex offenders; non sex offenders; characteristics; 


\section{A Comparison of Sex Offenders and Other Types of Offenders Referred to Intellectual Disability Forensic Services}

There has been an increasing interest in offenders with intellectual disability (ID) over the last 5 years (Lindsay, Hastings and Beech 2011). Research has been conducted on the prevalence of people with ID in prisons and other parts of the criminal justice system (Holland and Persson,2011,Jones and Talbot 2010), the legal context for the detention of offenders with ID (French, Chan and Carracher 2010, Webber et al 2010) and on pathways through the criminal justice system (Carson et al 2010, Lindsay et al 2010a,b.). There has also been a range of research on the assessment of risk (Camilleri and Quinsey 2011) and the way in which characteristics of offenders with ID may relate to the offences and risk (Lindsay et al 2010c, Lunsky et al 2011). Much of this work has been done considering offenders with ID as a single group while it is clear, in research on offenders and general, that various subgroups are often studied and compared.

Sex offenders have often been considered separately in the field of criminology. There are a number of journals which report research, clinical practice and theoretical developments in the field of sex offenders only, e.g. Sexual Abuse: $A$ Journal of Research in Practice, Journal of Sexual Aggression, Archives of Sexual Behaviour. It is clear that sexual offenders are considered to be an important, even independent, subsection of general offenders. The same separate interest has not been afforded to other categories of offending such as fire raising or acquisitive offences. There is no journal of Arson or journal of Theft offences. Rather, these categories are incorporated into research publications given over to general criminality or violent offending. Therefore, historically, 2 broad categories of offences have been considered, general offending and a specific subsection of sexual offending. 
Another area in which sex offenders have been considered as a separate population from non sexual offenders is in the field of risk assessment. Across all categories of risk assessment, violent offenders and sex offenders have separate instruments on which practitioners can calculate risk. In actuarial assessment, Quinsey et al $(1998,2006)$ have constructed the Sex Offender Risk Appraisal Guide (SORAG) and the Violence Risk Appraisal Guide (VRAG). Both assessments share several variables but each has specific idiomatic risk factors relevant to the client group. In the field of structured clinical judgement, again there are separate instruments for the appraisal of sexual and violent risk. For violent risk, the HCR-20 (Webster et al 1995) is used and for sexual risk, the SVR-20 (Boer et al 1997) is applicable. Again, both assessments share certain variables but each has specific factors relevant to the client group.

In the field of offenders with Intellectual Disability (ID) this convention has been maintained with some studies making comparisons between sexual offenders and all other, non sexual offenders. Glaser \& Deane (1999) compared 34 sexual offenders with 34 non offenders referred to their clinic. They found remarkably few differences between the 2 groups including, surprisingly, no differences in the relative history of sexual offences. They felt that offending in men with ID might reflect an underlying difficulty with impulsiveness which emerged and manifested itself in a range of problem behaviours. This would account for the lack of difference between the 2 groups on history of sex offending and suggests that the manifestation of impulsivity in these men was almost indiscriminate.

Lindsay et al $(2004,2006)$ also compared groups of sexual offenders and other types of offenders referred to their forensic ID service. In contrast to Glaser \& Deane (1999) they found significant differences between the 2 groups in offence type and in previous offending. The sex offenders had a very low rate of offending in other ways while the other types of offenders had almost no sexual offending in their history beyond a minimal amount of prostitution. In these studies, the 2 groups 
seemed quite distinct. They reported several significant differences in the developmental histories of the 2 groups including the fact that sex offenders reported higher levels of childhood sexual abuse in their history than non sexual offenders (36\% v 14\%) while the opposite was true for physical abuse in childhood with non sexual offenders reporting a higher rate than sexual offenders (34\% v 16\%) (Lindsay et al 2001). Lindsay et al (2006) found that sex offenders had lower rates of assessed anger and aggression, anxiety and alcohol or substance use difficulties; both groups had similar rates of diagnosed mental illness (around $32 \%$ ) and the sexual offenders had higher levels of sexual and relationship problems. Therefore, there were a number of specific differences between the 2 groups in these studies.

In another comparison testing the impulsivity hypothesis of Glaser \& Deane (1999), Parry \& Lindsay (2004) compared 36 sexual offenders with 34 other types of offenders on the Barratt Impulsiveness Scale (Barratt 1994). They found that sex offenders reported low levels of impulsivity on all dimensions of the scale. In a similar comparison on anxiety and depression, Lindsay \& Skene (2007) reported data on several categories of individuals with Intellectual Disability. These included 34 sex offenders, 31 other types of offenders and other participants referred to clinics for reasons of anxiety, depression and difficulties with challenging behaviour. The sex offender group reported the lowest levels of anxiety and depression when compared to all other groups. Steptoe et al (2006) have compared sexual offenders to violent offenders on aspects of quality of life and relationships. They found that sexual offenders had similar levels of assessed quality of life but reported poorer relationships. Therefore, there have been a number of studies comparing different groups of offenders that generally separate participants into sexual offenders and non sexual offenders.

There have been also been reports of fire raisers as a distinct group. These are generally records of assessment and treatment (e.g. Taylor et al 2002, 2007) and they do not constitute comparisons between fire raisers and other groups of 
offenders or non offenders. Therefore, there is a history of considering sex offenders as a distinct group and, occasionally, making comparisons with other types of offenders. Generally these comparisons have found sex offenders to have lower rates of emotionality, similar rates of mental illness and poorer interpersonal relationships when compared to other groups. As with mainstream offenders (Hanson et al 2002), researchers have found lower rates of reoffending among sexual offenders with ID when compared to other offenders (Lindsay et al 2006, Gray et al 2007). In relation to reoffending, Klimicki et al (1994) followed up offenders with ID released from prison. They found that sexual offenders had a lower rate of reoffending but cautioned that several were still in prison and so had little opportunity to offend.

However, many of the comparative results on sex offenders with ID have been reported from 1 research population in Scotland, UK (Parry and Lindsay 2003, Lindsay et al 2006, Lindsay and Skene 2007, Steptoe et al 2007). It may well be that this particular population has a number of idiosyncrasies that do not allow generalisations for all results. It is important to gather information on offenders from wider geographical and national locations.

The present study compares a cohort of sexual offenders with a cohort of non sexual offenders, all with ID, referred in 2003 to a number of forensic ID services across the UK.

\section{Method}

\section{Study Sites}

Several health board regions and 2 maximum secure hospitals served as locations for the study. All were included because they had a history of experience and expertise in dealing with offenders with ID at their level of security. These included a generic community service which accepted individuals who had committed 
offences or offending behaviour, specialist community forensic ID services, general ID in patient services, low secure, medium secure and maximum secure forensic ID services.

\section{Participants}

477 participants were included in the study meeting the following criteria:

1. They had been referred in the year 2002 and for maximum secure services, because of the low referral rate, in the years 2001 and 2002;

2. The referral related to antisocial or offending behaviour including physical aggression, verbal aggression, sexually inappropriate behaviour, cruelty and neglect of children, damage to property, fire setting, theft, motor vehicle or traffic related behaviours, obtaining goods or money under false pretences and illegal drug related behaviour;

3. They were aged 18 years by December $31^{\text {st }} 2002$.

\section{Ethical Approval}

Ethical approval was sought through the Scottish Committee for Medical Research Ethics. After some negotiation, approval was granted for England under a Section 60 Exemption of the Health and Social Care Act (2001) and for Scotland, under Caldicott Guardian approval.

\section{Materials and Procedure}

Four Research Assistants (RAs) were allocated to each of the main study areas and liaised with local clinical teams to extract information from the clinical files. The RAs used a standard form to gather all information. The form was guided by a manual (see end note). Data was gathered on demographic information, ethnicity, level of learning disability, possible medical diagnoses, psychiatric diagnoses, abuse experienced in childhood, referring agent, level of service referred to (described above), distance between residence and referred service, legal status on day of 
referral, legal status on day of index behaviour, index behaviour, age at time of index behaviour, charges, previous problematic behaviour and previous offending.

All RAs had at least graduate qualifications in psychology. They undertook a dedicated 1 week course in order to ensure consistency of data collection across sites. In order to ensure reliability, 3 anonymised cases were chosen by the grant holders. The cases were chosen for their diversity and complexity in order to ensure a range of information collected. One of the cases was randomly selected and was presented to the 4 RAs as a group. The group discussed how they would approach the interrogation of the case notes and how they would rate each of the questions. If there was any ambiguity or disagreement, the group made reference to the manual and worked through the issues until there was agreement to the decision they would take. Where this was not possible, the manual was returned to the clinicians and more specific guidance on coding was added. The second case was independently completed by the RAs and their responses compared. Once again, when there was disagreement on their coding, the RAs discussed their reasoning that led to their decision. After this second run through, the group were satisfied that the manual contained sufficient detail to allow reliable coding from the information contained in the case notes. The third case was used to test reliability of the questionnaire. Each RA again, independently completed the questionnaire based on this final set of case notes. Reliability was calculated comparing the responses of all four RAs to each question contained in the questionnaire. The proportion of questions that RAs responded in the same way was $85 \%$.

This is a significant level of agreement across 4 raters, since if 1 was discrepant; this was recorded as a disagreement. However, such a criterion (4 agreements on each item) was necessary for the purposes of this study. Although this level of agreement was deemed acceptable, a few problematic questions remained. The questions which were seen as the most problematic in terms of reliability were those requiring the RAs to identify the number of times a particular 
challenging behaviour or criminal act was mentioned in the notes. The RAs could reliably identify which category of behaviour was noted but were less reliable when coding how many different episodes where recorded in the notes. The options the RAs had to choose from were 1 incident, 2 to 5 incidents and over 5 incidents. This difficulty was largely due to the way in which some episodes of challenging or criminal behaviour had been described in the case notes, e.g. those responsible for writing up these notes often used the terms such as "numerous episodes", "repeated episodes" and so on. For the purposes of the particular descriptions in this paper, these problematic distinctions were collapsed and only the appearance or not of a behaviour was entered into the analysis.

Results

The results are presented in a series of tables giving information on referral source, information on the index behaviour, information on prior problem behaviours, diagnostic information and information on adversity in childhood. Because of the large number of comparisons in this study, we have considered it prudent to raise the alpha level to $1 \%$ and thus treat differences as significant only at the probability level of $1 \%$. For all of the tables in the results section, the percentage of each group classified under each category is shown, with the actual numbers in parenthesis. Percentages allow for an easier comparison between groups since there are different numbers in the sex offender and other offender groups. In some cases, there are too few instances with an individual group for $\chi^{2}$ to be completed. In these cases, we have used Fisher's Exact Probability test.

There were 131 sex offenders and 346 other types of offenders in this study. There were no females in the sex offender cohort and so all 97 females in the study were in the other offender group.

Table 1

Table 1 shows the source of referral for each group. For the purposes of the current paper, the comparison of interest is between sex offenders and the other 
participants. Therefore the security and other characteristics of the service to which the referral has been made have been collapsed leaving only the 2 groups of sex offenders and other offenders. The table presents the differences in referral source for both groups. There is a significant difference among referral sources as indicated by $\chi^{2}$ and this result achieves the required alpha. We therefore calculated the differences between groups for each referral source to ascertain the specific differences causing the overall effect. $\chi^{2}$ were completed for each pair of figures and 2 achieved significance at the required alpha. A significantly higher percentage of sexual offenders were referred from court $\left(\chi^{2}=11.2, p=0.000\right)$, and a significantly higher percentage of other offenders were referred from secondary healthcare $\left(\chi^{2}=\right.$ $7.03, p<0.01)$.

\section{Tables 2 and 3}

Table 2 shows a number of demographic and offence related variables. Only 1 achieves the required alpha indicating that a significantly higher percentage of sexual offenders had some form of legal status at time of referral. Legal status was recorded as any court disposal such as probation or community service, any detention or restriction order under mental health legislation, or guardianship orders. Since actual numbers in each category were relatively small, they were collapsed into one categorical variable of having legal status or not.

There were no differences between the groups on the IQ band recorded (Table 3), legal status at the time of the index behaviour, physical disability and whether or not they were charged with an index offence (this latter variable just fails to achieve the required alpha).

\section{Table 4}

Table 4 shows the percentage of each group on each index behaviour. The other types of offender showed significantly higher percentages on physical aggression, verbal aggression, cruelty and neglect, damage to property, fire starting 
and offences involving substance abuse. The sex offenders had significantly higher percentages recorded for the sexual offences (stalking, contact sexual and non contact sexual).

\section{Table 5:}

For previously recorded offences (table 5), a similar pattern emerges although the trends are not as strong. The other types of offenders have significantly higher recordings in previous physical aggression, verbal aggression, cruelty and neglect to children and substance abuse. The sex offenders have a significantly higher previous record of contact and non contact sexual offences.

\section{Table 6:}

Table 6 shows the incidence of psychiatric disturbance and childhood adversity recorded for the sexual offenders and the other types of offenders. Here, there were fewer significant differences between groups and only ADHD achieves the required alpha with other types of offenders having significantly higher recorded level in the case notes.

\section{Discussion}

This study has found some significant differences between groups of offenders with Intellectual Disability referred to services. In our comparisons between sex offenders and other types of offenders, the first obvious difference is that all the women referred to services for forensic problems where in the non sex offending group. This is similar to results found with the mainstream offenders in that the vast majority of sexual offenders are men. When we looked at referral source, a significantly higher proportion of sex offenders were referred from court and criminal justice services. Just over $20 \%$ of the sex offender referrals came from criminal justice services with only $10 \%$ of the other offenders. Perhaps the most surprising thing is that so few of the other types of offenders came from criminal justice sources. It may be that various services are more comfortable in dealing with violent, alcohol 
related and acquisitive offences. It may also be that the social interest and concern related to sexual offences makes individual services such as social services and community services more cautious when dealing with these individuals without reference to the courts and criminal justice. It was also the case that fewer sexual offenders were referred from secondary healthcare. Secondary healthcare included a range of learning disability services such acute wards and hospital clinic services that were able to refer to the study. These services may be an option for bypassing criminal justice agencies and when they consider certain offenders overly complex for treatment or when they feel they have been treated successfully for mental or physical illness but require further specialist offence related input, they then refer onto forensic ID services. These 2 referral sources were the main reasons for the significant differences between groups in this study.

In consideration of the index offences themselves, there were several differences between groups. Sexual offences were exclusively confined to the sexual offenders. This is tautological since if a sexual offence was involved in the index offence, then they would be categorised as a sexual offender. It was certainly the case that other offending behaviours were considered at the time of the index offence which gave rise to the sexual offenders registering in the other non sexual categories of offending. However, if a sexual offence was involved they were classified in the sexual group. In relation to all categories of offending, physical aggression was the most common followed by verbal aggression. Even if contact and non contact sexual offences are combined, physical aggression and verbal aggression remain the most common index behaviours. Here the other types of offenders have significantly higher rates than the sexual offenders. The same trend of higher rates in the other offender group was seen in the index behaviours of damage to property and substance abuse. Cruelty and neglect of children and fire setting as index behaviours were exclusive to the other offender group. 
A similar pattern was seen in the review of previous offending. Again, physical and verbal aggression was most commonly recorded as previous offending behaviour. For these two, there were significant differences with the other offenders showing higher levels than the sexual offenders. Between $20 \%$ and $25 \%$ of the other offenders had shown previous inappropriate sexual behaviour or sexual offending although these figures remained less than half of the previous sexual offending for the sex offender group. Therefore, although there was a clear statistical separation in terms of previous sexual offending, there was considerable overlap between the 2 groups. Similarly, there was overlap in rates of previous aggression although the other offenders had significantly higher rates. Two other previous behaviours reached the required alpha. The first was substance abuse where almost $25 \%$ of the other offenders had recorded previous substance abuse compared to just over $10 \%$ in the sexual offenders. Therefore, sexual offenders had a history of lower rates of substance abuse. The final significant difference reflected the fact that only 1 of the sex offender group had previously recorded cruelty and neglect of children while 27 of the other offender group had recorded this offence. While previous offences reflected current, index behaviours, the trend was not as strong.

There were few differences between groups reaching the required alpha for legal status, psychiatric disturbance and abuse in childhood. At the point of referral, more of the sex offenders had formal legal status which probably reflects the fact that a greater proportion of sex offenders were referred from criminal justice and court services. Although more sex offenders had been charged both currently and previously, these differences failed to reach the required alpha. None of the individual psychiatric diagnoses reached the required alpha although a diagnosis of ADHD fell just short. In this case the other offenders had a higher recorded rate of ADHD.

It is interesting that ADHD should emerge as the only psychiatric diagnosis to even approach significance in comparisons between the 2 groups. In a previous 
study on this client group, Lindsay et al (2009) found that ADHD was the most common psychiatric diagnosis in offenders with ID accepted into services. This variable is emerging as an important developmental indication for future offending behaviour in mainstream criminal groups (Collins and White 2002, Curran.and Fitzgerald 1999) but has not been researched with any rigour in offenders with ID. It would seem that an important area for future research is to review the extent to which ADHD can be identified as a developmental factor in offending. If it is identified as a significant factor, then it may be possible to take remedial action during an individual's teenage years to prevent any developmental trajectory that might lead him or her into offending. This would be an important area for service planning and clinicians were research results to support such a hypothesis.

None of the child abuse variables showed significant differences between groups. The trends were similar to previous research with sexual abuse more predominant in the sex offender group and physical abuse more predominant in the other offender group. However, these trends fell well short of significant differences between the groups. The most frequent recorded adversity in childhood was socioeconomic deprivation and again, there were no differences between the 2 groups.

Several trends emerged significantly from this study. Physical and verbal aggression was the most frequently recorded offences both in terms of the index behaviour and previous offending. This suggests that any service for forensic ID clients should include assessment and treatment measures to address issues of violence and aggression. Having said that, sexual offending was obviously a frequently referred problem and for the index behaviour, it was exclusively seen in the sex offenders. Therefore, if an individual is referred with a constellation of index behaviours (say, aggression, property damage and sexual offending), then they will be categorised as being referred for primarily a sexual offence and, subsequently, with complications of aggression and destructiveness. However, the other offenders 
did have sexual offending in their history at a reasonably significant rate of around 20 to $25 \%$.

\section{$\underline{\text { Acknowledgements }}$}

This study was funded by the UK. Dept. of Health National Forensic Health research and development Programme - research grant no. MRD/12/45

Note: copies of the proforma for data collection are available from

billlindsay@castlebeck.com 
Table 1: Referral source for the sexual and non sexual offenders. The table shows the percentages of each group referred from each source with actual numbers in parenthesis. The $\chi^{2}$ value of differences in groups and probability is also inserted. Asterisks reveal that the specific differences between groups for that referral source are significant at $1 \%$.

\begin{tabular}{|l|l|l|l|l|}
\hline Referral Source & Other Offenders & Sex Offenders & $\chi^{2}(\mathrm{df} 6)$ & $\mathrm{P}$ \\
\hline Self & $0.3(1)$ & $1.6(2)$ & 21.33 & 0.002 \\
\hline Community & $17.4(60)$ & $11.7(15)$ & & \\
\hline Social Services & $14.5(50)$ & $13.3(17)$ & & \\
\hline Court & $9.9(34)^{*}$ & $21.9(28)^{*}$ & & \\
\hline Primary HC & $6.4(22)$ & $4.7(6)$ & & \\
\hline Secondary HC & $28.4(98)^{*}$ & $17.2(22)^{*}$ & & \\
\hline Tertiary HC & $23.2(80)$ & $29.7(38)$ & & \\
\hline
\end{tabular}


Table 2: Legal status at referral and time of index behaviour, whether or not the individual was charged and previous charges. Percentages for each category in each group are inserted with actual numbers in parenthesis. $\chi^{2}$ value for the difference between groups and the probability for the significance of the difference is also included.

\begin{tabular}{|l|l|l|l|l|}
\hline \multicolumn{1}{|c|}{ Variable } & \multicolumn{1}{|c|}{$\begin{array}{c}\text { Other } \\
\text { Offenders }\end{array}$} & \multicolumn{1}{|c|}{$\begin{array}{c}\text { Sex } \\
\text { Offenders }\end{array}$} & $\chi^{2}(\mathrm{df} 1)$ & $\mathrm{P}$ \\
\hline Legal Status at Referral & $44.7(152)$ & $58.3(74)$ & 6.81 & 0.009 \\
\hline Legal Status at Index Behaviour & $28.9(100)$ & $35.1(46)$ & 1.74 & 0.419 \\
\hline Charged & $30.6(106)$ & $42.0(55)$ & 5.47 & 0.019 \\
\hline Previous Charges & $34.7(120)$ & $45.8(60)$ & 5.00 & 0.025 \\
\hline
\end{tabular}


Table 3 : Table $X$ shows the percentage of participants in each IQ band for both groups. $\chi^{2}$ and probability for the difference in the matrix of scores is included.

\begin{tabular}{|l|l|l|l|l|}
\hline \multicolumn{1}{|c|}{ IQ Band } & \multicolumn{1}{|c|}{$\begin{array}{c}\text { Other } \\
\text { Offenders }\end{array}$} & Sex Offenders & $\chi^{2}(\mathrm{df} 3)$ & P \\
\hline Borderline & $20.5(71)$ & $26.0(34)$ & 2.88 & 0.237 \\
\hline Mild & $49.7(172)$ & $53.4(70)$ & & \\
\hline Moderate & $16.5(57)$ & $11.5(15)$ & & \\
\hline Unknown & $13.3(46)$ & $9.2(12)$ & & \\
\hline
\end{tabular}


Table 4: Index offences. The percentage of each group, with actual numbers in parenthesis, recording each index offence; the $\chi^{2}$ result on the difference between groups and probability are also included.

\begin{tabular}{|l|l|l|l|l|}
\hline \multicolumn{1}{|c|}{ Index Offence } & \multicolumn{1}{|c|}{$\begin{array}{c}\text { Other } \\
\text { Offenders }\end{array}$} & \multicolumn{1}{|c|}{ Offenders } & \multicolumn{1}{c|}{$\chi^{2}(\mathrm{df} 1)$} & \\
\hline Physical Aggression & $57.5(119)$ & $24.4(32)$ & 41.7 & 0.000 \\
\hline Verbal Aggression & $37.3(129)$ & $22.1(29)$ & 9.8 & 0.002 \\
\hline Cruelty/Neglect to Children & $8.0(34)$ & $0.0(0)$ & 11.26 & 0.001 \\
\hline Stalking & $0.0(0)$ & $6.9(9)$ & 24.2 & 0.000 \\
\hline Contact Sex Offence & $0.0(0)$ & $52.7(69)$ & 213.1 & 0.000 \\
\hline Non Contact Sex Offence & $0.0(0)$ & $51.1(67)$ & 205.9 & 0.000 \\
\hline Property Damage & $22.0(76)$ & $11.5(15)$ & 6.8 & 0.009 \\
\hline Fire Starting & $5.8(20)$ & $0.0(0)$ & 7.9 & 0.002 \\
\hline Theft & $6.4(22)$ & $3.8(5)$ & 1.15 & 0.28 \\
\hline Traffic Offences & $1.7(6)$ & $0.0(0)$ & 2.3 & 0.129 \\
\hline Substance Abuse & $7.5(27)$ & $0.8(1)$ & 8.5 & 0.002 \\
\hline
\end{tabular}


Table 5: Previous offending: The percentage of each group, with actual numbers in parenthesis, recording each index offence; the $\chi^{2}$ result on the difference between groups and probability are also included.

\begin{tabular}{|l|l|l|l|l|}
\hline Previous Offending & \multicolumn{1}{|c|}{ Other Offenders } & Sex Offenders & $\chi^{2}(\mathrm{df} 1)$ & $\mathrm{P}$ \\
\hline Physical & $72.5(251)$ & $55.7(73)$ & 12.3 & 0.001 \\
\hline Verbal Aggression & $63.6(220)$ & $48.1(63)$ & 9.45 & 0.002 \\
\hline $\begin{array}{l}\text { Cruelty/Neglect to } \\
\text { Children }\end{array}$ & $7.8(27)$ & $0.8(1)$ & 8.52 & 0.004 \\
\hline Stalking & $2.9(10)$ & & & \\
\hline Contact & $21.4(74)$ & $4.6(6)$ & 0.84 & 0.257 \\
\hline Offence & & $54.2(71)$ & 48.35 & 0.000 \\
\hline Non Contact Sex & $24.9(86)$ & $60.3(79)$ & 52.78 & 0.000 \\
\hline Offence & & & 1.47 & 0.225 \\
\hline Property Damage & $43.6(151)$ & $33.6(44)$ & 3.97 & 0.029 \\
\hline Fire Starting & $18.2(63)$ & $16.8(22)$ & 0.13 & 0.415 \\
\hline Theft & $28.6(99)$ & $29.8(38)$ & 0.06 & 0.803 \\
\hline Traffic Offences & $8.7(30)$ & $5.8(7)$ & 9.51 & 0.002 \\
\hline Substance Abuse & $24.3(84)$ & $11.5(13)$ & & \\
\hline
\end{tabular}


Table 6: Psychiatric disturbance and adversity in childhood. Percentages, with actual numbers in parenthesis, are inserted for each category for both groups; $\chi^{2}$ values and the probabilities are also included.

\begin{tabular}{|l|l|l|l|l|}
\hline Diagnosis/Abuse & Other Offenders & Sex Offenders & $\chi^{2}(\mathrm{df} 1)$ & $\mathrm{P}$ \\
\hline Schizophrenia & $7.1(23)$ & $8.2(11)$ & 0.23 & 0.63 \\
\hline Other Psychosis & $12.6(43)$ & $11.3(14)$ & 0.27 & 0.60 \\
\hline Bipolar Disorder & $6.5(21)$ & $3.0(4)$ & 1.24 & 0.19 \\
\hline Depression & $12.7(43)$ & $6.7(9)$ & 3.02 & 0.08 \\
\hline Personality Disorder & $5.3(18)$ & $4.8(6)$ & 0.08 & 0.78 \\
\hline ASD & $8.8(28)$ & $9.1(12)$ & 0.16 & 0.68 \\
\hline ADHD & $17.6(61)$ & $9.1(12)$ & 5.26 & 0.02 \\
\hline Sexual Abuse & $9.8(34)$ & $13.0(17)$ & 0.99 & 0.32 \\
\hline Physical Abuse & $13.3(46)$ & $9.2(12)$ & 1.52 & 0.22 \\
\hline Deprivation & $24.1(83)$ & $26.6(34)$ & 0.13 & 0.73 \\
\hline
\end{tabular}




\section{References}

Barratt E. S. (!994) Impulsivity and aggression. In: Violence and Mental Disorder (eds J. Monahan \& H. J. Steadman),pp.61 - 79. University of Chicago Press, Chicago, IL.

Boer, D. P., Hart, S. D., Kropp, A. R. \& Webster, C. D. (1997) Manual for the Sexual Violence Risk - 20: Professional Guidelines for Assessing Risk of Sexual Violence. Vancouver, British Colombia: British Colombia Institute on Family Violence and Mental Health, Law and Policy Institute, Simon Fraser University.

Carson' D., Lindsay W.R., O’Brien G., Holland A.J., Taylor J.T., Wheeler J.R., Middleton C., Price, K., Steptoe I. \& Johnston, S. (2010). Referrals into services for offenders with intellectual disabilities: Variables predicting community or secure provision. Criminal Behaviour and Mental Health, $\underline{20}, 39-50$

Collins, P and White T. (2002) Forensic implications of attention de.cit hyperactivity disorder (ADHD) in adulthood. Journal of Forensic Psychiatry and Psychology, 13, $263-84$

Curran, S. \& Fitzgerald, M (1999) Attentional Deficit Hyperactivity Disorder in the Prison Population. American Journal of Psychiatry, 156, 1664-5

French P, Chan J \& Carracher R. (2010). Realising human rights in clinical practice and service delivery to persons with cognitive impairments who engage in behaviours of concern. Psychiatry, Psychology and Law, 17, $245-272$.

Glaser, W. \& Deane, K. (1999) Normalisation in an Abnormal World: A Study of Prisoners with Intellectual Disabilities. International Journal of Offender Therapy and Comparative Criminology, 43, 338-50.

Hanson, R. K., Gordon, A., Harris, A. J. R., Marques, J. K., Murphy, W., Quinsey, V. L. \& Seto, M. C. (2002) First Report of the Collaborative Outcome Data 
Project on the Effectiveness of Psychological Treatment for Sex Offenders. Sexual Abuse: A Journal of Research and Treatment, 14, 169-94.

Holland, S. and Persson P. (2011) intellectual disability 10in the Victorian prison system: characteristics of prisoners with an intellectual disability released from prison in 2003 - 2006. Psychology, Crime and Law, 17, 25 - 42.

Jones G and Talbot J. (2010) No One Knows: the bewildering passage of offenders with a learning disability and learning difficulty through the criminal justice system. Criminal Behaviour and Mental Health, 20, 1-7.

Klimecki, M. R., Jenkinson, J. \& Wilson, L. (1994) A Study of Recidivism among Offenders with Intellectual Disability. Australia and New Zealand Journal of Development Disabilities (Journal of Intellectual and Developmental Disabilities), 19, 209-19.

Lindsay WR., Carson' D.,R., O'Brien, G., Holland A.J.Johnston, S.,,Taylor J.,L., Wheeler J.R., Middleton C., Price, K., Steptoe L, \& Johnston S.(2010b) The relationship between assessed risk and security level for offenders with intellectual disabilities. Journal of Forensic Psychiatry and Psychology, 21, $537-540$.

Lindsay, W. R., Law, J., Quinn, K., Smart, N. \& Smith, A. H. W. (2001) A Comparison of Physical and Sexual Abuse Histories: Sexual and None Sexual Offenders with Intellectual Disabilities. Child Abuse and Neglect, 23, 989-95.

Lindsay WR., O’Brien, G., Carson' D.,R., Holland A.J.,Taylor J.,L., Wheeler J.R., Middleton C., Price, K., Steptoe L, \& Johnston S.(2010a) Pathways into services for offenders with intellectual disabilities: Childhood experiences, diagnostic information and offence related variables. Criminal Justice and Behaviour, 37, 678-94

Lindsay, W. R., \& Skene, D. D. (2007) The Beck Depression Inventory II and The Beck Anxiety Inventory in People with Intellectual Disabilities: Factor 
Analyses and Group Data. Journal of Applied Research in Intellectual Disability, 20, 401-8

Lindsay, W. R., Smith, A. H. W., Law, J., Quinn, K., Anderson, A., Smith, A., \& Allan, R. (2004) Sexual and Non Sexual Offenders with Intellectual and Learning Disabilities: A Comparison of Characteristics, Referral Patterns and Outcomes. Journal of Interpersonal Violence, 19, 875-90.

Lindsay, W. R., Steele, L., Smith, A. H. W., Quinn, K. \& Allan, R. (2008) A Community Forensic Intellectual Disability Service: 12 Year Follow up of Referrals, Analysis of Referral Patterns and Assessment of Harm Reduction. Legal and Criminological Psychology, 11, 113-30.

Lindsay, W. R., Allan, R., Parry, C., Mcleod, F., Cottrell, J., Overand, H., \& Smith, A. W. (2004) Anger and Aggression in People with Intellectual Disabilities: Treatment and Follow up of Consecutive Referrals and Waiting List Comparison. Clinical Psychology and Psychotherapy, 11, 255-64.

Lindsay, WR., Taylor, J., Hogue, T., Steproe. L., Mooney P. and Morrisey C.(2010c)cThe relationship between assessed emotion, personality, personality disorder and risk. Psychiatry, Psychology and Law, 17, 385 - 397.

Lindsay, W. R., Holland, A. J., Taylor, J. L., Michie, A. M., Bambrick, M. B., O’Brien, G., Carson, D., Steptoe, L., Middleton, C., Price, K. \& Wheeler, J. (2009) Diagnostic Information and Adversity in Childhood for Offenders with Learning Disability Referred to and Accepted into Forensic Services. Advances in Mental Health and Learning Disabilities, 3, 19-24.

Lunsky Y., Gracey, C., Koegl C. et al (2011) the clinical profile and service needs of psychiatric inpatients with intellectual disabilities and forensic involvement. Psychology Crime and Law, 17, 9-25 
Parry, C. \& Lindsay, W. R. (2003) Impulsiveness as a Factor in Sexual Offending by People with Mild Intellectual Disabilities. Journal of Intellectual Disability Research, 47, 483-87.

Quinsey, V. L., Harris, G. T., Rice, M. E. \& Cormier, C. A. (2006) Violent Offenders: Appraisal and Managing Risk, Second Edition. American Psychological Association, Washington, DC.

Steptoe, L., Lindsay, W. R., Forrest, D. \& Power, M. (2006) Quality of Life and Relationships in Sex Offenders with Intellectual Disability. Journal of Intellectual and Developmental Disabilities, 31, 13-19.

Taylor, J. L., Robertson, A., Thorne, I., Belshaw, T. \& Watson, A. (2005) Responses of Female Fire Setters with Mild and Borderline Intellectual Disabilities to a Group Based Intervention. Journal of Applied Research in Intellectual Disabilities, 19, 179-90.

Taylor, J. L., Thorne, J., Robertson, A. \& Avery, G. (2002) Evaluation of a Group Intervention for Convicted Arsonists with Mild and Borderline Intellectual Disabilities. Criminal Behaviour and Mental Health, 12, 282-93.

Webber LS, Lambrick F., Donley M. et al (2010). Restraint and seclusion of people on compulsory treatment orders in Victoria, Australia in $2008-2009$. Psychiatry, Psychology and Law, 17, 562 - 573.

Webster, C. D., Eaves, D., Douglas, K. S. \& Wintrup, A. (1995) The HCR-20: The Assessment of Dangerousness and Risk. Vancouver, Canada: Simon Fraser University and British Colombia Forensic Psychiatric Services Commission. 